\title{
Gestão ambiental em empresas públicas e sociedades de economia mista do estado de Minas Gerais
}

\author{
Environmental management in public companies and semi-public corporations \\ of Minas Gerais
}

\author{
Jéssica Patrícia Bernardes da Silva ${ }^{1}$ \\ Sabrina Soares da Silva ${ }^{2}$ \\ Raphaela da Silva Mendes ${ }^{3}$
}

\begin{abstract}
Resumo
As empresas públicas e sociedades de economia mista, pressionadas a se posicionarem de modo responsável diante das questões ambientais, adotam programas, projetos e ações ligadas à gestão ambiental. Nesse sentido, o objetivo deste estudo foi identificar os modelos e ações de gestão ambiental utilizados pelas empresas públicas e sociedades de economia mista do estado de Minas Gerais. A partir da coleta de dados relacionados à dimensão ambiental, foi possível analisar os modelos e ações de gestão desenvolvidos em cada empresa e como relacioná-los com as abordagens de gestão ambiental. Os resultados revelaram que os modelos mais implementados foram o licenciamento ambiental e a responsabilidade social. Já a educação ambiental e o sistema de gestão ambiental estiveram presentes em um número menor de organizações. As sociedades de economia mista investiram mais em tais modelos. Concluiu-se que as medidas adotadas precisam ser ampliadas na maioria das organizações, a fim de auxiliarem na busca por soluções de problemas ambientais, beneficiando o meio ambiente, a economia e a sociedade.
\end{abstract}

Palavras-Chave: Gestão Ambiental. Empresas Públicas. Sociedade de economia mista.

\begin{abstract}
Public and Semi-Public Corporations, pressed to take environmentally responsible positions, use programs, projects and actions related to environment management. In this sense, this paper aims to identify models and environmental management actions used by Public and Semi-Public Corporations of the Minas Gerais State. From the data related to the environmental dimension collected, we could analyze the models and management actions developed in each company and relate them to the environmental management approaches. The results showed that the models implemented commonly were the environmental licensing and social responsibility. Environmental education and environmental management systems were represented in fewer organizations. The Semi-Public Corporations invested more in such models. It was concluded that the models need to be adopted more frequently in more organizations to assist in the search for environmental problems solutions, benefiting the environment, the economy and society as a whole.
\end{abstract}

Keywords: Environmental Management. Public Companies. Semi-Public Corporations.

\section{Introdução}

A preocupação com o meio ambiente têm se destacado cada vez mais, tanto em âmbito nacional quanto em dimensão internacional, devido aos problemas causados pela interferência do homem. Por um período considerável de tempo os recursos naturais vinham sendo utilizados sem que se levasse em conta sua escassez, e, como consequência, surgiram problemas ambientais, como poluição e desmatamento,

Mestrado em Desenvolvimento e Tecnologias Sociais pela Universidade Federal de Itajubá - UNIFEI. Brasil. Afiliação: Universidade Federal de Lavras - UFLA. Lattes: http://lattes.cnpq.br/1210693059960641. Email: jessicabernardes18@hotmail.com

Departamento de Administração e Economia. Afiliação: Universidade Federal de Lavras - UFLA. Brasil. Email: sabrinasilva@dae.ufla.br

3 Mestrado em Desenvolvimento Sustentável e Extensão pela Universidade Federal de Lavras - UFLA. Brasil. Afiliação: Universidade Federal de Lavras - UFLA. Lattes: http://lattes.cnpq.br/1511202656177145. Email: raphaelacobain@hotmail.com 
que ganharam proporções globais, a ponto de levarem as lideranças dos países a se reunirem em busca de soluções. Nesses encontros, passaram a discutir e idealizar o estabelecimento de um modelo de desenvolvimento sustentável.

De fato, a sociedade hoje está mais preocupada com o meio ambiente do que em relação ao período anterior à década de 1930, quando as práticas diretas adotadas pelo poder público passaram a ocorrer, por enxergar as consequências de negligenciá-lo e temer a intensificação dos problemas, por isso pressionam o Estado e as organizações para se comprometerem com a preservação do meio ambiente, bem como com a racionalização do uso dos recursos naturais.

Entre essas e outras questões ambientais estão as demandas públicas que o Estado busca atender, de acordo com suas possibilidades, por meio da Constituição e de leis regulamentadoras. Assim, as políticas públicas ambientais são orientadoras das ações do Estado em prol do meio ambiente, de forma que a gestão ambiental pública pode ser entendida como a "ação do poder público conduzida segundo a política pública ambiental" (BARBIERI, 2007, p. 71). Essa gestão envolve programas, projetos e ações para tratar os problemas ambientais.

As empresas públicas devem estar alinhadas ao Estado para promoverem qualidade ambiental com o intuito de proporcionar condições ao desenvolvimento socioeconômico (BRASIL, 1981). Nesse sentido, as empresas públicas e as sociedades de economia mista, enquanto integrantes do Estado, são corresponsáveis pela conservação e preservação do meio ambiente e, portanto, devem atuar de modo que essas questões sejam observadas em sua atuação.

Nas organizações, a gestão ambiental representa a operacionalização da política ambiental. Portanto, identificar os modelos e ações de gestão ambiental dessas instituições possibilita conhecer o seu funcionamento, bem como qual seu foco em tais preocupações. Para conquistar uma gestão ambiental efetiva, é necessária uma estruturação organizacional envolvendo todos os níveis hierárquicos da empresa, para que todos os seus funcionários conheçam e se orientem pela política ambiental implementada. Sendo assim, esta deve ser norteadora da atuação da empresa e, portanto, envolve o planejamento, o gerenciamento, os modelos, as abordagens e as ações desenvolvidas pela empresa.

Os modelos de gestão ambiental orientam atividades administrativas e operacionais e, por isso, são importantes para atingir os resultados esperados (BARBIERI, 2009; VILELA JÚNIOR; DEMAJOROVIC, 2013). Todavia, as organizações podem desenvolver ações isoladas que não se caracterizam como um modelo de gestão ambiental. Diante do exposto, apresenta-se a questão da pesquisa: Quais são os modelos e as ações de gestão ambiental utilizados pelas empresas públicas e sociedades de economia mista do estado de Minas Gerais? Para responder a esse questionamento, este trabalho objetivou identificar os modelos e as ações de gestão ambiental adotados pelas empresas públicas e sociedades de economia mista do estado de Minas Gerais.

Diante dos problemas ambientais atuais, da constatação de que os níveis correntes de utilização dos recursos naturais e de emissão de resíduos pela humanidade não podem ser mantidos e de que as implicações ambientais das diversas atividades não são consideradas na análise de projetos e investimentos, vários países e estados, como Minas Gerais, passaram a considerar tais preocupações em seu planejamento. Para que o estado possa estimular o processo de mudança efetiva, é preciso que também as organizações a ele ligadas passem por esse processo, indicando que estão sensíveis aos problemas socioambientais, que há comprometimento com a mudança, e servindo como exemplo.O planejamento do estado deixa claro seu comprometimento com as questões ambientais. Contudo, há ainda poucos estudos analisando como as ações planejadas têm sido efetivamente implementadas pelas organizações públicas.

\section{Preocupações ambientais do Estado brasileiro}

Barbieri (2009) afirma que as práticas diretas adotadas pelo poder público em favor do meio ambiente ocorreram apenas na década de 1930. As primeiras manifestações dos governos, quanto aos problemas ambientais, tinham caráter corretivo. Portanto, a solução era buscada apenas após sua ocorrência. $\mathrm{Na}$ 
década de 1970, as medidas tratavam os problemas de modo isolado e localizado. Somente a partir da década de 1980 passaram a ser tratados de forma generalizada e interdependente.

No Brasil, em 31 de agosto de 1981, foi publicada a Lei $n^{\circ}$ 6.938, que dispõe sobre a Política Nacional do Meio Ambiente (PNMA), onde é conferida ao Estado e à sociedade a responsabilidade de se comprometerem com as questões ambientais. Essa política tem como objetivo a preservação, melhoria e recuperação da qualidade ambiental, visando assegurar condições ao desenvolvimento socioeconômico, aos interesses da segurança nacional e à proteção da dignidade da vida humana (BRASIL, 1981).

A qualidade do meio ambiente é considerada fundamental para o desenvolvimento da sociedade como um todo. Os princípios da PNMA atribuem ao governo o dever de articular um conjunto de ações que visam uma melhor relação com o meio ambiente, bem como de envolver os indivíduos na proteção ao meio ambiente. $\mathrm{O}$ artigo $12^{\circ}$ da PNMA ainda prevê a concessão de créditos a empreendimentos cujos projetos passem pela aprovação do licenciamento ambiental, orientados pelo Conselho Nacional do Meio Ambiente (CONAMA), que é uma função atribuída às entidades e órgãos governamentais de financiamento (BRASIL, 1981).

A PNMA rompe com a perspectiva de subordinação das questões ambientais ao desenvolvimento econômico pelo fato de apontar a necessidade de equilíbrio entre as dimensões ambiental, social e econômico como fator fundamental para a qualidade de vida dos indivíduos (SEIFFERT, 2007). Barbieri (2009) destaca sua importância como política pública, visto que é a condutora da gestão pública ambiental. Essa importância foi reforçada, em 1988, quando a Constituição Federal brasileira incluiu o meio ambiente em um capítulo específico, que o destaca como um direito coletivo e atribui ao poder público a responsabilidade de zelar por sua garantia a todos os cidadãos. Em seu artigo 225 é estabelecido que todos têm direito ao meio ambiente ecologicamente equilibrado. Ele é considerado um bem de uso comum e essencial à qualidade de vida. Cabe ao poder público e à coletividade defendê-lo e preservá-lo para as presentes e futuras gerações (BRASIL, 1988).

\subsection{Das preocupações ambientais das organizações à inserção do ambiental na gestão}

Nos últimos anos, foi possível perceber uma mudança no discurso das organizações quanto às questões socioambientais, impulsionadas pelo desenvolvimento de legislações ambientais a partir de diversos dispositivos da Constituição Federal de 1988 (BARBIERI, 2009). A maior cobrança por parte dos indivíduos para que as empresas recompensem os impactos causados por suas ações, não apenas no meio social e econômico, mas no ambiente como um todo, também motivou as organizações a mudarem seus discursos (SILVA; SANTINELLI; MACHADO, 2012). Essas motivações também ganham força na Conferência das Nações Unidas (Rio +20) que aconteceu no ano de 2012, na cidade do Rio de Janeiro, a partir de acordos internacionais firmados por estados, entidades governamentais, empresas e organizações não governamentais preocupados com questões ecológicas (VIZEU, 2012).

Entretanto, Layrargues (2000) acredita que a sensibilização do setor produtivo frente às variáveis socioambientais não foi motivada por razões ecológicas, como alguns discursos empresariais defendem, mas por razões econômicas. Embora prevaleça a ideia de que a preocupação ambiental no processo produtivo leve à elevação de custo, algumas empresas a enxergam como uma oportunidade de inserção no mercado e de aumento da competitividade (DONAIRE, 1999). A incorporação de questões ambientais na atuação da organização também pode proporcionar benefícios, como lucro pela redução de custos (MACHADO; OLIVEIRA, 2013). Corroborando com essas concepções, Vizeu (2012) afirma que as organizações se apropriam das concepções de sustentabilidade visando encaixá-las dentro dos contextos e dos discursos que atendam aos seus interesses pragmáticos.

De acordo com Dias (2009), no Brasil, o nível de preocupação organizacional quanto ao meio ambiente apresenta uma relevante disparidade, fato que influencia a decisão de incluí-la, ou não, no planejamento estratégico. Entre os fatores envolvidos nas escolhas realizadas por uma empresa, constam os valores compartilhados em âmbito interno. Contudo, Vizeu (2012, p.579) afirma que, as pressuposições dominantes no conceito de desenvolvimento sustentável ignoram que as organizações capitalistas, em 
sua estrutura, "[...] carecem de solidariedade interna uma vez que legitima a distribuição dos resultados da atividade empresarial de forma desproporcional em favor dos níveis superiores de direção".

Entretanto, as soluções para os problemas ambientais envolvem um contexto complexo de questões econômicas, políticas, sociais e culturais. que interferem em diferentes medidas em sua viabilidade ou andamento. A gestão ambiental, entendida como diretrizes e atividades administrativas e operacionais, traz o desafio de lidar com fatores inseridos em cada uma dessas dimensões com o intuito de encontrar um caminho factível de amenizar, eliminar e evitar os problemas causados pela interferência humana na natureza (BARBIERI, 2009). Para Machado e Oliveira (2013), embora a gestão ambiental tenha se iniciado para atender às exigências das leis e às pressões externas, passou posteriormente a abordar medidas preventivas e, atualmente, vem conquistando espaço no meio empresarial devido à variedade de modelos e instrumentos para implementá-la.

A gestão ambiental pode ser entendida como a gestão empresarial com objetivo de atingir o desenvolvimento sustentável, ao respeitar os limites do meio ambiente, de modo que os problemas sejam evitados (DIAS, 2009). Ela pode constituir uma ferramenta fundamental para a sustentabilidade, proporcionando vantagem competitiva para as organizações (DEMAJOROVIC, 2013; DONAIRE, 1999). A gestão ambiental é composta por três esferas: política ambiental, planejamento ambiental e gerenciamento ambiental. Esses elementos devem ser articulados de forma que a política ambiental constitua uma dimensão maior, representante dos interesses da sociedade e do governo. Ela é instituída por meio de um conjunto de princípios doutrinários que orientam a regulamentação, assim como ações de controle, proteção e conservação ambiental (SEIFFERT, 2007).

Segundo Seifert (2007), a política ambiental exerce influência na elaboração do planejamento e no gerenciamento, portanto, devem estar alinhados conforme os princípios doutrinários da organização. A importância dessa política para o processo de gestão ambiental é acentuada em sua implementação. $\mathrm{Na}$ esfera pública, cabe ao governo fazer isso com objetivos claros, tendo em vista as possibilidades de atingir determinado resultado dentro de uma realidade. Para isso, as ações estratégicas escolhidas devem ser aliadas à criação de instituições que as executem, bem como à estruturação de uma legislação que as amparem.

A partir do que está previsto na política ambiental, o planejamento busca analisar as possibilidades de ações relacionadas ao uso, controle, proteção e conservação do meio ambiente. Já o gerenciamento diz respeito às ações regulatórias e à avaliação de uma determinada situação. É importante destacar que gestão ambiental e gerenciamento ambiental são termos diferentes. Este último possui um caráter tático, enquanto o primeiro é classificado como estratégico e implica na implementação da política (SEIFFERT, 2007).

Dependendo da atuação da organização em relação aos problemas causados pelo desempenho de suas atividades, podem ocorrer três tipos de abordagens de gestão ambiental: o controle da poluição, a prevenção da poluição e a abordagem estratégica. O controle da poluição, como já se pode concluir, busca definir medidas inibidoras de poluição, tendo um caráter reativo, pois as soluções são executadas após a ocorrência do resíduo poluidor e geralmente são utilizadas ações pontuais (BARBIERI, 2009). Albuquerque (2013) considera que essa abordagem atua em um nível simples, cujo objetivo é evitar conflitos ecológicos, por meio do tratamento de um problema. Duas soluções tecnológicas se encaixam nessa abordagem. A primeira é a remediação, que busca reparar um dano já ocorrido. A segunda é o controle no final do processo (end-of-pipe), que normalmente envolve mais de um tipo de tecnologia. Todavia, ambas as soluções nem sempre são eficazes, pois as substâncias poluentes podem apenas mudar de forma.

Embora essa abordagem seja considerada uma solução insuficiente e de custo elevado, sua ausência poderia piorar o quadro de problemas ambientais. Por isso, deve ser vista como uma alternativa importante, pois contribui para amenizar os níveis de poluição já existentes (BARBIERI, 2009).

$\mathrm{Na}$ abordagem de prevenção da poluição, a organização deve buscar medidas que previnam a formação de resíduos no processo produtivo, utilizando uma quantidade menor de produtos e energia. Desse modo, é promovido o uso de recursos sustentáveis, consoante ao ideal dos 4R's: reduzir, reutilizar, reciclar e recuperar. Nessa abordagem, a prioridade é diminuir a quantidade de resíduos e reutilizar os 
materiais. A reciclagem visa transformar produtos usados em aproveitáveis novamente, podendo ser realizada no ambiente interno ou externo da organização. Contudo, alguns materiais requerem cuidados com a segurança e podem gerar custos elevados e, por isso, é comum as empresas transferirem esse trabalho para outras organizações, especialistas nessa função. Por fim, a recuperação energética busca a produção de energia por meio da utilização de materiais com potencial de gerar calor (BARBIERI, 2009).

A terceira abordagem é chamada de estratégica por buscar soluções ambientais por meio de um conjunto de ações que gere valores positivos para a empresa, reconhecidos e identificados pelo público, proporcionando vantagens competitivas sustentáveis e diferenciação. Sabe-se que os consumidores estão cada vez mais preocupados com o comprometimento das organizações nesse sentido, por isso, assumir esse comprometimento pode ser uma oportunidade mercadológica (BARBIERI, 2009). Essa abordagem é similar à definida como proativa por Albuquerque (2013), a qual se refere às ações ambientais vistas como oportunidades vantajosas e, por isso, incorporadas às estratégias empresariais para direcionar a visão dos gestores.

A implementação de qualquer abordagem de gestão ambiental é feita por meio de diferentes atividades organizacionais, orientadas por diferentes concepções. Tais atividades caracterizam os diferentes modelos e ações de gestão ambiental. Os modelos adotados neste estudo são: o sistema de gestão ambiental (SGA), a responsabilidade social empresarial (RSE), a produção mais limpa ( $P+L)$ e a ecoeficiência. Já as ações são o licenciamento ambiental e a educação ambiental.

O sistema de gestão ambiental é uma metodologia subordinada aos princípios de uma política ambiental, pela qual as empresas buscam atingir uma gestão efetiva nesse âmbito. Pode derivar de uma política reativa se utilizar métodos corretivos como base para soluções de problemas, ou de uma política proativa e se os métodos tiverem caráter preventivo. Embora este último seja o ideal, por tratar a causa do problema, a maioria das empresas opta pelo método corretivo (DIAS, 2009).

Vale ressaltar que a implantação da SGA em pequenas empresas ainda é um desafio, pois sua implantação requer um investimento de alto valor para atender às exigências da norma ISO 14001, responsável por seu regimento e pela definição dos requisitos a serem cumpridos, através de uma série de ferramentas e sistemas padronizados (DIAS, 2009). Esse sistema envolve, além do cumprimento de procedimentos todos os componentes da estruturação empresarial, como o planejamento e os recursos humanos, financeiros e materiais. Os benefícios gerados por essa mobilização geral da estrutura organizacional refletem a melhoria na imagem da empresa e nos processos desenvolvidos, o que consequentemente a torna mais competitiva (ALBUQUERQUE; OLIVEIRA, 2009).

A responsabilidade social empresarial integra a dimensão ambiental (DIAS, 2009) e consiste em um conjunto de ações baseadas em um compromisso contínuo, com questões sociais internas e externas à organização a fim de promover a qualidade de vida para a sociedade como um todo (ASHLEY, 2001 apud PENA et al., 2007). Para o Instituo Ethos (2013), a responsabilidade social é definida como "a forma de gestão que se define pela relação ética e transparente da empresa com todos os públicos com os quais se relaciona e pelo estabelecimento de metas empresariais que impulsionem o desenvolvimento sustentável da sociedade" (INSTITUTO ETHOS, 2013, p.16).

A dependência e a constante interação do ser humano com o meio ambiente devem ser levadas em consideração na responsabilidade social empresarial estabelecida pelas organizações. $\mathrm{O}$ social e ambiental estabelecem uma relação interdependente, pois os indivíduos possuem uma demanda contínua por recursos naturais para garantir sua sobrevivência e desenvolvimento, logo, a preservação do meio ambiente é a solução ideal para que as gerações futuras também tenham suas necessidades atendidas. Assim, as ações devem ser articuladas, de modo que o resultado proporcionado entre elas convirja em melhorias para a qualidade de vida.

A RSE se divide em dimensão interna e externa. A primeira está associada aos funcionários, distribuidores e fornecedores, portanto, cuida da qualidade dos fatores essenciais para o desenvolvimento do trabalho, entre eles, os recursos naturais no processo produtivo. Já o aspecto externo é amplo, envolve diversos atores da sociedade e do Estado na busca pela defesa do meio ambiente (DIAS, 2009). 
A produção mais limpa e a ecoeficiência conciliam os interesses de mercado às exigências legais. Com caráter preventivo, buscam utilizar totalmente os recursos a fim de evitar desperdícios e resíduos poluentes no processo produtivo (SEIFFERT, 2007).

A $\mathrm{P}+\mathrm{L}$ pode ser abordada em três níveis, são eles: $\mathrm{O}$ nível 1 , que se refere às alternativas de prevenção da poluição em sua fonte; o nível 2, que diz respeito às sobras de resíduos, portanto, devem ser encaminhados para reutilização interna; e o nível 3, que ocorre quando uma substância não pode ser aproveitada internamente, sendo necessário o encaminhamento à reciclagem externa. $E$ quando não for possível realizar o processo de reciclagem, os resíduos devem ser destinados a um lugar seguro (BARBIERI, 2009). Quanto aos benefícios proporcionados pela $\mathrm{P}+\mathrm{L}$, estendem-se à organização, à comunidade, ao meio ambiente e aos responsáveis pelo controle ambiental (GASI; FERREIRA, 2013).

A ecoeficiência é a produção de bens e serviços com a racionalidade de recursos, enquanto permite melhorias para a qualidade de vida e mantém os produtos a preços competitivos (WBCSD, 1996 apud VIEIRA, 2013). A ecoeficiência possui três objetivos centrais: redução do consumo dos recursos, redução do impacto na natureza e melhoria do valor do produto ou serviço. A lógica da ecoeficiência e da atividade empresarial são compatíveis, pois não existe uma restrição ao crescimento, pelo contrário, permite aumento de lucro, conquista e melhoria de posicionamento no mercado, bem como a redução de custos operacionais. Essa vantagem despertou a atenção das organizações ao vê-la sob uma perspectiva de supervalorização. Embora importante, não deve ser compreendida como uma solução perfeita e única para se alcançar o desenvolvimento sustentável (DEMAJOROVIC, 2013).

O Programa das Nações Unidas para o Meio Ambiente (PNUMA) aponta sua preferência pela ecoeficiência, por abranger todo o ciclo de vida do produto, enquanto que a $P+L$ se restringe à prevenção. Além disso, o nível de prioridade da reciclagem interna e externa é maior na ecoeficiência (BARBIERI, 2009).

Já o licenciamento ambiental é um mecanismo preventivo da Política Nacional do Meio Ambiente que busca adequar as atividades dos empreendimentos a fim de proteger a qualidade ambiental no processo de desenvolvimento socioeconômico (SEIFFERT, 2007). Em outras palavras, é a ação para adequar os empreendimentos à legislação ambiental, conforme o impacto gerado pelo desenvolvimento de suas atividades. Trata-se de um processo composto por três fases, conforme as definições da Resolução $n^{\circ} 237$ do Conselho Nacional do Meio Ambiente (CONAMA), de 19 de dezembro de 1997.

A primeira fase é a de licença prévia (LP), onde são analisadas a viabilidade e as condições de implementação do projeto por meio da elaboração do Estudo de Impacto Ambiental (EIA) e do Relatório de Impacto Ambiental (RIMA). O EIA é um instrumento de análise mais amplo sobre o potencial de degradação ao meio ambiente de projetos e obras (BARBIERI, 2009). O RIMA é semelhante a ele, porém, seu conteúdo é elaborado em uma linguagem de fácil compreensão e mais detalhada. Essa diferenciação visa estimular a participação da comunidade, de modo que os indivíduos possam entender as informações contidas no documento e contribuir efetivamente nas audiências públicas (DONAIRE, 1999; SEIFFERT, 2007).

O EIA e o RIMA contribuem para a Avaliação de Impactos Ambientais (AIA), instrumento de caráter preventivo que identifica os impactos ambientais para que o empreendedor adote medidas sistemáticas a fim de reduzi-los ou amenizá-los (SEIFFERT, 2007). Em uma análise crítica, Sánchez (2013) afirma que, devido ao desconhecimento da AIA por partes dos gestores, tem sido pouco abordada na gestão ambiental, embora tenha a função de planejar e organizar.

A segunda fase é a de licença de instalação (LI), onde constam as medidas relacionadas aos fatores físicos que devem ser implementadas. A última fase depende do cumprimento da LI. Se todas as exigências forem atendidas, o funcionamento do empreendimento é autorizado (SEIFFERT, 2007).

A principal dificuldade enfrentada pelas empresas no licenciamento ambiental é a lentidão burocrática do processo (CNI, 2004). Diante desse empecilho, Dias (2009) aponta a necessidade de simplificação aliada à padronização das decisões. Além disso, ressalta que os órgãos do Sistema Nacional do Meio Ambiente (SISNAMA), responsáveis pelo licenciamento ambiental, devem possuir uma melhor definição quanto às suas competências, bem como implementar políticas de informação a fim de garantir um processo mais transparente. 
Além dos meios de gestão ambiental voltados para os problemas decorrentes da poluição de um processo produtivo, tem-se a educação ambiental. Segundo Silva (s.d., apud ALCÂNTARA et al.,2012), é um caminho para às organizações contribuírem com a disseminação e incorporação de valores ambientais, influenciando, desse modo, a formação de cidadãos com atitudes responsáveis em relação ao meio ambiente.

De acordo com a Lei n 9.795, de 1999, que institui a Política Nacional de Educação Ambiental, a educação ambiental é compreendida como processos por meio dos quais o indivíduo e a coletividade constroem valores sociais, conhecimentos, habilidades, atitudes e competências voltadas para a conservação do meio ambiente, essencial à sadia qualidade de vida e sua sustentabilidade (BRASIL, 1999). Logo, é uma possibilidade para estimular a atuação empresarial, preocupada em ser efetiva na defesa do meio ambiente. Neste sentido, a educação ambiental pode ser aliada para a conservação das unidades ambientais com a cooperação da comunidade ao redor dessas áreas, por meio da conscientização e sensibilização para essa causa (PÁDUA, 2012).

Portanto, a educação ambiental deve desenvolver uma cultura organizacional a fim de fortalecer a gestão ambiental, e um caminho para alcançá-la é a execução de programas que se materializam basicamente em três formatos, são eles: Ações pontuais, limitadas às palestras para os funcionários da organização; trabalho realizado com o público externo, como o apoio às escolas em questões ambientais; a implementação da norma NBR ISO 14001, orientadora do sistema de gestão ambiental, o que implica a inserção da preocupação ambiental em todos os níveis hierárquicos da empresa (SIMONS, 2013).

A gestão ambiental pode ser exercida pelas organizações por meio de diferentes modelos e ações, que podem indicar um maior ou menor comprometimento com essas questões, o que pode indicar qual a abordagem adotada pela organização para tratar das questões ambientais.

\section{Metodologia}

Esta é uma pesquisa documental, descritiva e classifica-se como qualitativa, pois busca descrever determinadas características das organizações estudadas, possibilitando estabelecer relações entre algumas variáveis (GIL, 2008).

O corpus da pesquisa são empresas públicas e sociedades de economia mista do estado de Minas Gerais ligadas à diferentes secretarias. Foram selecionadas seis organizações (quadro I), três empresas públicas e três sociedades de economia mista, que tiveram mais conteúdo disponibilizado sobre a dimensão ambiental.

Quadro 1- Empresas do estado de Minas Gerais analisadas.

\begin{tabular}{|l|l|l|}
\hline \multicolumn{1}{|c|}{ Empresa } & \multicolumn{1}{c|}{ Tipo } & \multicolumn{1}{c|}{ Vinculação } \\
\hline $\begin{array}{l}\text { Banco de Desenvolvimento de Minas } \\
\text { Gerais - BDMG }\end{array}$ & Empresa pública & $\begin{array}{l}\text { Secretaria de Estado de } \\
\text { Desenvolvimento Econômico }\end{array}$ \\
\hline $\begin{array}{l}\text { Companhia Energética de Minas Gerais - } \\
\text { CEMIG }\end{array}$ & $\begin{array}{l}\text { Sociedade de economia } \\
\text { mista }\end{array}$ & $\begin{array}{l}\text { Secretaria do Desenvolvimento } \\
\text { Econômico }\end{array}$ \\
\hline $\begin{array}{l}\text { Companhia de Saneamento de Minas } \\
\text { Gerais - COPASA }\end{array}$ & $\begin{array}{l}\text { Sociedade de economia } \\
\text { mista }\end{array}$ & $\begin{array}{l}\text { Secretaria de Estado de } \\
\text { Desenvolvimento Regional e Política } \\
\text { Urbana }\end{array}$ \\
\hline $\begin{array}{l}\text { Companhia de Desenvolvimento do } \\
\text { Estado de Minas Gerais - CODEMIG }\end{array}$ & $\begin{array}{l}\text { Sociedade de economia } \\
\text { mista }\end{array}$ & $\begin{array}{l}\text { Secretaria do Desenvolvimento } \\
\text { Econômico }\end{array}$ \\
\hline $\begin{array}{l}\text { Empresa de Assistência Técnica e } \\
\text { Extensão Rural de Minas Gerais - } \\
\text { EMATER }\end{array}$ & Empresa pública & $\begin{array}{l}\text { Secretaria de Estado de Agricultura, } \\
\text { Pecuária e Abastecimento }\end{array}$ \\
\hline $\begin{array}{l}\text { Empresa de Pesquisa Agropecuária do } \\
\text { Estado de Minas Gerais - EPAMIG }\end{array}$ & Empresa pública & $\begin{array}{l}\text { Secretaria de Estado de Agricultura, } \\
\text { Pecuária e Abastecimento }\end{array}$ \\
\hline
\end{tabular}

Fonte: Dados da pesquisa (2015). 
A coleta de dados foi realizada por meio de consultas a conteúdos de materiais documentais, como relatórios, balanços, cartilhas e notícias, que estavam disponíveis nos sítios eletrônicos de cada uma das organizações estudadas. Os dados coletados permitiram a reunião de informações com o objetivo identificar os principais modelos e ações de gestão ambiental utilizados pelas empresas públicas e sociedades de economia mista do estado de Minas Gerais.

A análise dos dados foi realizada por meio da análise de conteúdo. A análise se iniciou com a busca de dados relacionados à unidade de registro, referências à dimensão ambiental, relacionando-a com a unidade de contexto para cada organização. Em seguida, foram identificados os modelos e ações de gestão ambiental desenvolvidos em cada organização, os quais foram relacionados com as abordagens de gestão. Os modelos e ações de gestão ambiental foram classificadas nas categorias de análise apresentadas por Barbieri (2009) e Seifert (2007): SGA, RSE, P+L, ecoeficiência e educação ambiental. As ações para a adequação à legislação ambiental foram classificadas em licenciamento ambiental, EIA e RIMA, conforme as orientações de Vilela Júnior e Demajorovic (2013). A partir dessas identificações, buscou-se classificar os modelos e ações de gestão ambiental de cada empresa nas abordagens desenvolvidas por Barbieri (2009): controle da poluição, prevenção da poluição e estratégica. Por fim, foi realizada uma comparação entre os resultados das empresas públicas e sociedades de economia mista.

\section{Análise da gestão ambiental das empresas públicas de Minas Gerais}

O BDMG (2014) investe em questões ambientais para promover o desenvolvimento sustentável com a visão de ser o banco indispensável para o desenvolvimento de Minas Gerais. Nota-se a busca pela visibilidade e posicionamento da organização, o que pode revelar interesses de competitividade. As ações tiveram caráter preventivo, corretivo e de preservação, portanto, somado ao interesse de competitividade, classifica-se na abordagem estratégica conforme as definições de Barbieri (2009). A atuação da organização vai além de um caráter corretivo e preventivo, pois envolve um conjunto de ações que geram valores positivos para a empresa e são reconhecidos e identificados pelo público, proporcionando vantagens competitivas e diferenciação.

O licenciamento ambiental foi citado em todas as linhas de financiamentos ofertadas aos empreendimentos cuja atividade é potencialmente poluidora e se encontra regularizada conforme as exigências da legislação ambiental (BRASIL, 1981). A SER também pode ser observada em programas ou linhas de créditos que incorporam a questão ambiental. Outras ações também são desenvolvidas e visam contribuir para o uso racional dos recursos naturais por meio do estímulo de práticas menos poluentes (BDMG, 2014).

O modelo de ecoeficiência, conceituado por WBCSD (1996) e citado por Vieira (2013), foi identificado na linha de crédito Apoio a Projetos de Eficiência e Energética (Proesco), bem como no Programa de Identificação de Projetos para o Desenvolvimento Sustentável de Minas Gerais.

Também é possível retomar a importância do $P+L$, de acordo com Seiffert (2007), no que foi obtido pela linha de financiamento Produção Mais Limpa, focada na concessão de crédito para práticas de produção que beneficiem o meio ambiente por meio de uma menor geração de resíduos, o que proporciona vantagens para as empresas, como a diminuição dos custos e maior competitividade e eficiência (BDMG, 2014).

Já as preocupações ambientais da EMATER se relacionam com seu setor de atuação, o de assistência técnica ao produtor rural. A prevenção da poluição, conceituada por Barbieri (2009), foi identificada em programas, projetos e ações que se referem à amenização, prevenção e recuperação de áreas degradadas pelas atividades de produção desenvolvidas no meio rural. O caráter preventivo, que vai além do corretivo, indica que a organização adota medidas que previnam a formação de resíduos no processo produtivo, priorizando reduzir a quantidade de resíduos.

A organização utiliza a gestão ambiental para promover a adequação de propriedades rurais. Além disso, afirma apoiar a educação ambiental (EMATER, 2010). No entanto, não foram evidenciados investimentos pontuais nesse âmbito. 
A P $+\mathrm{L}$, conforme define Seiffert (2007), foi identificada no Programa Agricultura de Baixo Carbono $(A B C)$ e no Integração Lavoura-Pecuária-Floresta (ILPF). O primeiro visa diminuir a emissão de gases causadores de efeito estufa por meio da oferta de créditos para propriedades regularizadas que atendem as exigências da legislação ambiental (CNA, 2012). Por sua vez, o ILPF, integrado ao programa ABC, objetiva unir a pecuária, agricultura e floresta em uma mesma área de produção a fim de obter vantagens, como menor degradação e redução da emissão de dióxido de carbono (EMATER, 2014). De acordo com a classificação de Barbieri (2009), essas ações se inserem na prevenção da poluição.

Assim como a EMATER, as preocupações ambientais da EPAMIG são focadas no âmbito rural. A organização realiza recuperação de áreas degradadas, porém não evidencia ações pontuais nesse sentido. A ecoeficiência, conforme conceituada por WBCSD (1996) e citado por Vieira (2013), foi observada no Programa Agroenergia, executado pela empresa que tem o objetivo de ampliar, apoiar e disseminar o conhecimento sobre agroenergia, bem como racionalizar os recursos por meio de práticas ambientais que possibilitem uma agricultura sustentável (EPAMIG, 2014). O uso de tecnologia limpa indica a prevenção da poluição, conforme conceitua Barbieri( 2009). Além de estratégias corretivas, a organização apresenta uma abordagem preventiva na gestão ambiental, buscando aderir a medidas que previnam a formação de resíduos no processo produtivo e priorizando a diminuição da quantidade de resíduos.

O licenciamento ambiental, definido por Seiffert (2007), foi observado no Projeto de Adequação Socioeconômica e Ambiental das Propriedades Rurais, que trabalha com a regulamentação das propriedades através de um EIA (BARBIERI 2009), para autorizar o licenciamento ambiental (EPAMIG, 2013). Portanto, classifica-se na prevenção da poluição, conforme Barbieri (2007), por evitar o impacto ambiental nas propriedades.

É utilizada para realizar esse projeto a metodologia Indicadores de Sustentabilidade em Agroecossistemas (ISA), com o objetivo de compreender a propriedade como um todo, verificando fatores de influência e interdependência presentes no agroecossistema em que a propriedade se insere, para, desse modo, obter uma base para conduzi-la ao desenvolvimento de práticas sustentáveis (EPAMIG, 2013). Por evidenciar estudos prévios sobre o impacto das atividades desenvolvidas nas propriedades, classifica-se na prevenção da poluição.

\section{Análise da gestão ambiental das empresas de economia mista de Minas Gerais}

Os modelos apresentados pela Cemig evidenciaram uma gestão estruturada, baseada na abordagem estratégica, em que a questão ambiental é vista por Barbieri (2009) como uma oportunidade, além de estar presente em toda a organização. A organização, além de sua atuação na gestão ambiental, de forma corretiva e preventiva, busca promover uma imagem positiva da empresa e um maior reconhecimento pelo público.

A empresa investe em questões ambientais em busca de se tornar líder mundial em sustentabilidade, obtendo reconhecimento, valorização de ações e melhoria na imagem (CEMIG, 2014), o que evidencia perspectiva de vantagem competitiva para que o posto de liderança seja conquistado.

Entre os modelos apresentados, consta o SGA, que, conforme explicado por Seiffert (2007), serve para adequar as atividades de acordo com a interferência no meio ambiente. Tal modelo é dividido em três níveis: Requisitos mínimos de adequação ambiental, SGA 1 e o ISO 14001. Entre as exigências do SGA consta a política ambiental da organização. Como apontada por Dias (2009), é peça fundamental para sua atuação frente aos problemas ambientais, classificando-se como estratégica, segundo Barbieri (2009), por envolver a alta administração.

Os princípios apresentados nessa política revelam a incorporação da questão ambiental em todos os níveis da empresa, como aponta o compromisso com a legislação, o planejamento e a preocupação com o impacto das atividades desenvolvidas.

O licenciamento ambiental também é importante para regulamentar o impacto das atividades desempenhadas por uma empresa, conforme as explicações de Seiffert(2007), e, na Cemig, é uma das principais iniciativas promovidas pela empresa para determinar e avaliar a viabilidade de empreendimentos 
com potencial de danos ao meio ambiente (CEMIG, 2014). Por possuir caráter preventivo, classifica-se na abordagem de prevenção da poluição BARBIERI, 2009).

A organização realiza ainda o EIA e o RIMA, baseados nas definições de Barbieri (2009) e Seiffert (2007), ambos possibilitam conhecer os possíveis efeitos a serem desencadeados pela implementação de projetos de empreendimentos cujas atividades possam interferir no meio ambiente. Por ser preventivo, também se insere na abordagem de Barbieri (2009) de prevenção da poluição.

No caso da Cemig, as atividades desenvolvidas em suas unidades geram impacto sobre a fauna dessas áreas devido à instalação de barragens que impedem o fluxo natural de espécies nativas e as ameaçam de extinção. Diante disso, realiza a RSE, conforme definida pelo Instituto Ethos (2013), por meio de projetos e programas ambientais destinados ao público (CEMIG, 2014).

O modelo ecoeficiência, conforme descrito por Seiffert (2007), foi identificado no uso de alternativas energéticas renováveis, como a biomassa, que emite menos dióxido de carbono se comparada aos combustíveis fósseis, como o carvão vegetal (CEMIG, 2014).

Também foram apresentados investimentos em energia eólica, o que caracteriza uma prática associada à $P+L$ segundo as descrições de Seiffert (2007). Os estudos sobre expansão e eficiência desse tipo de energia são apoiados a fim de identificar locais com potencial eólico, bem como incentivar a criação de geradores que permitam desenvolvê-la em regiões montanhosas (CEMIG, 2014). Essas iniciativas da ecoeficiência e P+L indicam a busca da prevenção da poluição (BARBIERI2007), devido à substituição e ao uso suficiente dos insumos, assim como pela utilização de tecnologias limpas.

A educação ambiental, conforme descreve Simons (2013), foi observada por meio de alguns investimentos, como o programa Terra da Gente, que oferece suporte ao educador escolar, e a Semana do Meio Ambiente, um incentivo artístico que visa à promoção da conscientização ambiental, especialmente de alunos e professores. Da mesma forma, o Centro de Educação Permanente de Três Marias promove eventos ambientais, que visam prevenir problemas ambientais através da conscientização e de atitudes ambientalmente responsáveis, portanto, se insere na prevenção da poluição conforme conceitua Barbieri (2007).

Já na abordagem controle (BARBIERI, 2007), foram identificadas ações, como o Manual de arborização que orienta e estimula o plantio de árvores, bem como o peixamento, cujo objetivo é introduzir peixes na usina com o auxílio da comunidade. (CEMIG, 2014).

A COPASA, assim como a CEMIG, apresentou uma gestão ambiental estruturada em programas, projetos e ações orientados por uma política ambiental., A organização enxerga a questão ambiental como uma oportunidade para conquistar lucro e manter boas relações com clientes e fornecedores, portanto, caracteriza-se como estratégica conforme o conceito de Barbieri (2007). A abordagem estratégica vai além da corretiva e preventiva, pois busca também envolver um conjunto de ações que geram valores positivos para a empresa e podem levar a uma imagem positiva, proporcionando vantagens competitivas sustentáveis.

Quanto à política ambiental da COPASA (2014), está fundamentada em princípios norteadores do modelo SGA, conceituado conforme Dias (2009), para conhecer e tratar os impactos causados no meio ambiente devido ao desempenho das atividades realizadas (COPASA, 2014).

A prevenção da poluição, conceituada por Barbieri (2009), foi identificada em ações preventivas e corretivas, como o licenciamento ambiental, e nas atividades com potencial de impacto sobre os recursos hídricos. Além disso, têm-se o Sistema Integrado de Proteção de Mananciais (SISAM), que visa conciliar a oferta de água tratada aos usuários e a preservação de bacias hidrográficas (COPASA, 2014).

A educação ambiental (SIMONS, 2013) foi identificada em eventos e projetos com o público externo e interno (COPASA, 2014). A RSE, conforme a definição de Dias (2009), foi identificada na coleta seletiva do lixo e na Estação de Tratamento de Esgoto Arrudas, responsável por receber esgoto, removendo resíduos e materiais orgânicos de diversos tipos (COPASA, 2014). A organização também assume o papel de agente coletor dessas substâncias (COPASA, 2014). Essas ações se classificam no controle da poluição, de acordo com o conceito de Barbieri (2007). 
Por fim, as preocupações ambientais demonstradas pela CODEMIG se referem às suas relações com os parceiros, como fornecedores e prestadores de serviços, no sentido de conhecer a procedência dos recursos a serem utilizados em suas obras e trabalhos (CODEMIG, 2014).

Apesar da CODEMIG (2014) afirmar possuir uma política de gestão ambiental cuja meta é o "dever de compatibilizar o desenvolvimento econômico e a conservação do meio ambiente", não oferece dados detalhados sobre esse assunto. A única evidência apresentada pela empresa é referente à construção do projeto da Cidade Administrativa, onde foi abordada a RSE, conceituada por Simons (2013). O foco se limitou a reduzir o impacto ambiental decorrente de sua criação. Em todo o espaço, há um cuidado com resíduos produzidos, uso racional dos recursos, reaproveitamento e baixo consumo de energia.

O controle da poluição, proposto por Barbieri (2009), foi identificado no sistema de esgoto à vácuo, que diminui a quantidade de água utilizada em $80 \%$ e possui capacidade própria para tratá-lo. Outra ação relacionada à correção de problemas é a coleta seletiva implantada na Cidade Administrativa (CODEMIG, 2014). Tudo isso indica que a empresa visa medidas inibidoras de poluição e, portanto, suas ações possuem caráter reativo.

\section{Comparações entre sociedades de economia mista e empresas públicas}

Os modelos de gestão ambiental e ações para a adequação ambiental identificados revelaram resultados diferentes entre as empresas e as sociedades de economia mista do estado de Minas Gerais. Quanto às sociedades de economia mista (quadro 2), observou-se que a CEMIG foi a única empresa a contemplar os seis modelos de gestão ambiental: SGA, RSE, P+L, ecoeficiência, licenciamento ambiental e educação ambiental. Na COPASA foram identificados quatro modelos de gestão ambiental, são eles: SGA, RSE, licenciamento ambiental e educação ambiental. Já na CODEMIG identificou-se apenas a RSE.

Quadro 2 - Modelos de gestão ambiental e ações para a adequação ambiental em sociedades de economia mista do estado de Minas Gerais analisadas.

\begin{tabular}{|l|c|c|c|}
\hline \multirow{2}{*}{\multicolumn{1}{|c|}{ Modelos/Ações }} & \multicolumn{3}{c|}{ Organizações } \\
\cline { 2 - 4 } & CEMIG & CODEMIG & COPASA \\
\hline SGA & $\mathrm{x}$ & & $\mathrm{x}$ \\
\hline RSR & $\mathrm{x}$ & $\mathrm{x}$ & $\mathrm{x}$ \\
\hline $\mathrm{P}+\mathrm{L}$ & $\mathrm{x}$ & & \\
\hline Ecoeficiência & $\mathrm{x}$ & & $\mathrm{x}$ \\
\hline Licenciamento ambiental & $\mathrm{x}$ & & $\mathrm{x}$ \\
\hline Educação ambiental & $\mathrm{x}$ & & \\
\hline
\end{tabular}

Fonte: dados da pesquisa (2015).

A RSE foi o único modelo presente nas três sociedades de economia mista, o que revelou a preocupação com desenvolvimento sustentável, conforme as definições do Instituto Ethos (2013). A P+L foi identificada apenas na CEMIG, o que aponta para o baixo investimento as tecnologias limpas. O SGA, o licenciamento ambiental e a educação ambiental foram identificados, na CEMIG e COPASA.

Os modelos de gestão ambiental e ações para a adequação ambiental apresentados também revelaram resultados diferentes entre as empresas públicas do estado de Minas Gerais (quadro 3). 
Quadro 3 - Modelos de gestão ambiental e ações para a adequação ambiental em empresas públicas do estado de Minas Gerais analisadas.

\begin{tabular}{|c|c|c|c|}
\hline \multirow[b]{2}{*}{ Modelos/Ações } & \multicolumn{3}{|c|}{ Organizações } \\
\hline & BDMG & EMATER & EPAMIG \\
\hline \multicolumn{4}{|l|}{ SGA } \\
\hline SER & $x$ & & \\
\hline$P+L$ & $x$ & $x$ & \\
\hline Ecoeficiência & $x$ & & $x$ \\
\hline Licenciamento ambiental & $x$ & & $x$ \\
\hline Educação ambiental & & & \\
\hline
\end{tabular}

Fonte: dados da pesquisa (2015).

Foram identificados quatro modelos/ações no BDMG, são eles: RSE, $P+L$, ecoeficiência e o licenciamento ambiental. A EPAMIG apresentou apenas a ecoeficiência e o licenciamento ambiental. A EMATER, por sua vez, apenas a P+L.

A ecoeficiência e o licenciamento ambiental foram apresentados no BDMG e na EPAMIG, enquanto que a $P+L$ foi encontrada no BDMG e na EMATER. Já a RSE foi identificada apenas no BDMG. Por fim, o SGA e a educação ambiental não foram identificados em nenhuma das empresas públicas.

Enquanto a RSE foi a mais identificada entre as sociedades de economia mista, a ecoeficiência e o licenciamento ambiental foram os mais abordados pelas empresas públicas. Nas sociedades de economia mista, SGA, P+L e ecoeficiência foram os modelos menos identificados; já nas empresas públicas, foram SGA e educação ambiental.

A presença da política ambiental na CEMIG e na COPASA pode ser um fator contribuinte para a diversificação do modelo de gestão ambiental em relação às demais, uma vez que influencia o planejamento e o gerenciamento conforme conceitua Barbieri (2007). Em contrapartida, ambos os lados possuem organizações mais restritas nesse sentido. No caso, a CODEMIG e a EMATER.

Pode ser estabelecida uma relação parecida com a inexistência da educação ambiental nas empresas públicas, pois a gestão nesse âmbito depende da criação de uma cultura ambiental entre os indivíduos (SIMONS, 2013). Portanto, a ausência desse modelo pode ser explicada pela ausência, ou baixa valorização, dessa dimensão.

Pode-se afirmar que entre as organizações do estado de Minas Gerais analisadas neste trabalho, as sociedades de economia mista apresentaram uma maior quantidade de modelos de gestão ambiental e ações para a adequação ambiental na comparação com as empresas públicas.

\section{Conclusão}

Os resultados obtidos demonstraram que os modelos de gestão ambiental mais identificados foram a RSE e o licenciamento ambiental, enquanto a implementação de um SGA e da educação ambiental foi menor. Entretanto, os modelos de gestão ambiental precisam, na maioria das organizações, ser ampliados a fim de auxiliarem nas soluções de problemas, beneficiando, assim, o meio ambiente, a economia e a sociedade como um todo.

As sociedades de economia mista investiram em mais modelos quando comparadas às empresas públicas. O capital privado, no âmbito empresarial, é um fator associado à busca pelo lucro, influenciando na atuação da organização frente às questões ambientais, visto que podem gerar competitividade, redução de custos e aumento de produtividade. No entanto, esperava-se que as empresas públicas tivessem mais ações e modelos de gestão ambiental, especialmente por se tratarem de empresas que devem visar o atendimento ao interesse público. Como o bem-estar da sociedade está vinculado à qualidade ambiental, esperava-se que essas empresas teriam como um de seus interesses centrais a preservação ambiental. 
Notou-se, ainda, entre as duas organizações que mais contemplaram modelos de gestão (CEMIG e COPASA), a implementação de uma política ambiental interna que orienta a organização a basear suas ações em seus princípios, além da presença da educação ambiental. Entretanto, seria interessante também aumentar o foco em educação ambiental, disseminando o conhecimento sobre questões referentes a esse assunto para estimular a conscientização e incentivar os indivíduos a adotarem práticas responsáveis, e consequentemente cumprirem com seu papel como cidadãos. Desse modo, as organizações estariam estimulando atitudes diárias e influenciando na preocupação quanto ao impacto de empreendimentos no meio ambiente. Tais práticas deveriam fazer parte do cotidiano das empresas, pois cabe aos gestores incentivar os colaboradores a implementar e manter iniciativas ambientais. Deve partir dos gestores o exemplo de responsabilidade ambiental, com alterações que visem minimizar o impacto ambiental não apenas no processo produtivo, mas também nas atividades administrativas (FINGER, MORETTO NETO, VIEIRA, 2010, p. 228).

A necessidade de maior participação dos gestores de empresas públicas e de economia mista é fundamental para incentivar práticas que busquem continuamente a responsabilidadeambiental . Há muitas discussões, dadas as incertezas envolvidas no conceito, sobre o que pode ser caracterizado como desenvolvimento sustentável por ser esse um fenômeno mutante e eclético, como defendem Munk e Souza (2011). Contudo, considera-se a busca por uma definição necessária atualmente, principalmente devido ao agravamento das questões ambientais.

A fonte de dados se restringiu ao conteúdo dos sítios eletrônicos das empresas públicas e sociedades de economia mista, podendo não constar determinados modelos ou ações adotadas, de fato, pelas organizações. Todavia, pode servir de base para pesquisas futuras que abordem os modelos de gestão ambiental. Quanto aos estudos posteriores, sugere-se a melhor exploração das razões pelas quais as empresas EPAMIG e EMATER não estão adotando outros modelos.

\section{Referências}

ALBUQUERQUE, J. L.; OLIVEIRA, C. V. Economia e meio ambiente. In: ALBUQUERQUE, J. L (Org.). Gestão ambiental e responsabilidade social: conceitos, ferramentas e aplicações. São Paulo: Atlas, 2009. p.48-69.

ALCÂNTARA, L. A.; SILVA, M. C. A. S.; NISHIJIMA, T. Educação ambiental e os sistemas de gestão ambiental no desafio do desenvolvimento sustentável. Revista Eletrônica em Gestão, Educação e Tecnologia Ambiental, Santa Maria (RS), v.5, n.5, p. 734-740, 2012.

BANCO DE DESENVOLVIMENTO DE MINAS GERAIS- BDMG. Disponível em: <http://www.bdmg. mg.gov.br>. Acesso em: 17 out. 2014.

BARBIERI, J. C. Gestão ambiental empresarial: conceitos, modelos e instrumentos. 2. ed. São Paulo: Saraiva, 2007.

BRASIL. Constituição da República Federativa do Brasil de 1988 . Disponível em: <http://www.planalto. gov.br/ccivil_03/Constituicao/Constituicao.htm>. Acesso em: 15 out. 2014.

BRASIL. Lei $n^{\circ}$ 6.938, de 31 de agosto de 1981. Dispõe sobre a Política Nacional do Meio Ambiente, seus fins e mecanismos de formulação e aplicação, e dá outras providências. Disponível em: <http:// www.planalto.gov.br/ccivil_03/leis/L6938compilada.htm>. Acesso em: 20 set. 2014.

BRASIL. Lei n 9.795, de 27 de abril de 1999. Dispõe sobre a educação ambiental, institui a Política Nacional de Educação Ambiental e dá outras providências. Disponível em: <http://www.planalto.gov.br/ ccivil_03/Leis/L9795.htm>. Acesso em: 26 out. 2014.

COMPANHIA DE DESENVOLVIMENTO ECONÔMICO DE MINAS GERAIS- CODEMIG. Disponível em: <http://www.codemig.com.br>. Acesso em: 17 out. 2014.

COMPANHIA DE SANEAMENTO DE MINAS GERAIS- COPASA. Disponível em: <http://www.copasa. com.br>. Acesso em: 06 out. 2014. 
COMPANHIA ENERGÉTICA DE MINAS GERAIS- CEMIG. Disponível em: <http://www.cemig.com.br>. Acesso em: 14 out. 2014.

CONFEDERAÇÃO DA AGRICULTURA E PECUÁRIA DO BRASIL - CNA. Guia de financiamento para agricultura de baixo carbono. Disponível em: <http://www.emater.mg.gov.br/doc/intranet/upload/ilps/ ilps\%20guia\%20financ.\%202012\%20cna.pdf>. Acesso em: 10 out. 2014.

CONFEDERAÇÃO NACIONAL DA INDÚSTRIA- CNI. Sondagem Especial da CNI. Disponível em:<http://arquivos.portaldaindustria.com.br/app/cni_estatistica_2/2014/10/13/135/SE12MAI2004.pdf>. Acesso em: 04 nov. 2014.

DEMAJOROVIC, J. Ecoeficiência em serviços: diminuindo impactos e aprimorando benefícios ambientais. In: VILELA JUNIOR, A.; DEMAJOROVIC; J. Modelos e Ferramentas de Gestão Ambiental: desafios e perspectivas para as organizações. São Paulo: Senac, 2013. p. 115-146.

DIAS, R. Gestão ambiental: responsabilidade social e sustentabilidade. São Paulo: Atlas, 2009.

DONAIRE, D. Gestão ambiental na empresa. 2. ed. São Paulo: Atlas, 1999.

EMPRESA DE ASSISTÊNCIA TÉCNICA E EXTENSÃO RURAL DE MINAS GERAIS- EMATER-MG. Disponível em: <http://www.emater.mg.gov.br >. Acesso em: 08 out. 2014.

EMPRESA DE PESQUISA AGROPECUÁRIA DE MINAS GERAIS- EPAMIG. Disponível em: <www. epamig.com.br >. Acesso em: 05 mai. 2013.

FINGER, L.; MORETTO NETO, L.; VIEIRA, B. G. Análise do sistema de gestão ambiental do Laboratório de Camarões Marinhos da Universidade Federal de Santa Catarina. Revista de Ciência da Administração, Santa Catarina, v. 12, n. 27, p. 208-231, maio/ago. 2010.

GASI, T. M. T.; FERREIRA, E. Produção mais limpa. In: VILELA JUNIOR, A.; DEMAJOROVIC; J.

Modelos e Ferramentas de Gestão Ambiental: desafios e perspectivas para as organizações. São Paulo: Senac, 2013. p. 45-82.

GIL, A. C. Métodos e técnicas de pesquisa social. 6. ed. São Paulo: Atlas, 2008.

INSTITUTO ETHOS. Glossário. Disponível em: <http://www3.ethos.org.br/wp-content/uploads/2013/09/ Gloss\%C3\%A1rio-Indicadores-Ethos-V2013-09-022.pdf> Acesso em: 05 nov. 2014.

LAYRARGUES, P. P. Sistemas de gerenciamento ambiental, tecnologia limpa e consumidor verde: a delicada relação empresa-meio ambiente no eco capitalismo. Revista de Administração de Empresas, São Paulo, v. 40, n. 2, p.88-80, abr./jun. 2000.

MACHADO, A. G. C.; OLIVEIRA, R. L. Gestão ambiental corporativa. In: ALBUQUERQUE, J. L (org.). Gestão Ambiental e Responsabilidade Social: conceitos, ferramentas e aplicações. São Paulo: Atlas, 2009. Cap. 5, p. 93-112.

MUNK, L.; SOUZA, R. B. O ecletismo do paradigma da sustentabilidade: construção e análise a partir dos estudos organizacionais. Revista de Ciências da Administração, Santa Catarina, v. 13, n. 29, p. 202-242, jan./abr. 2011.

PÁDUA, S. M.; SÁ, L.M. O papel da educação ambiental nas mudanças paradigmáticas da atualidade. Revista Paranaense de Desenvolvimento, Curitiba, n. 102, p.71-83, jan./jun. 2002.

PENA, R. P. et al. Responsabilidade social empresarial estratégica: um estudo sobre a gestão do público interno em duas empresas signatárias do global compact. Organizações \& Sociedade. Salvador, v.14, n.40, p. 81-98, jan./mar.2007.

SÁNCHEZ, L. E. Avaliação de impacto ambiental e seu papel na gestão de empreendimentos. In: VILELA JUNIOR, A.; DEMAJOROVIC; J. Modelos e ferramentas de gestão ambiental: desafios e perspectivas para as organizações. São Paulo: Senac, 2013. p. 115-146. 
SEIFFERT, M. E. B. Gestão ambiental: instrumentos, esferas de ação e educação ambiental. 2.ed. São Paulo: Atlas, 2007.

SILVA, S. S.; SANTINELLI, F.; MACHADO, J. C. Sustentabilidade e questões ambientais, sociais e econômicas nos discursos das empresas estatais de minas gerais. In: ENCONTRO NACIONAL DE PESQUISADORES EM GESTÃO SOCIAL, 7., 2012, Belém. Anais... Belém: Enapegs, 2012. p. 795-809.

SIMONS, M. O. Educação ambiental na empresa: mudando uma cultura. In: VILELA JUNIOR, A.; DEMAJOROVIC; J. Modelos e ferramentas de gestão ambiental: desafios e perspectivas para as organizações. São Paulo: Senac, 2013. p. 201-220.

VIEIRA, C. W. Análise custo-efetividade de ações empresariais em ecoeficiência, 2013. 107 p. Dissertação (Mestrado em Planejamento Estratégico) - Universidade Federal do Rio de Janeiro, Rio de Janeiro, 2013.

VILELA JUNIOR, A; DEMAJOROVIC, J. Modelos e ferramentas de gestão ambiental: desafios e perspectivas para as organizações. São Paulo: Senac, 2013.

VIZEU, F.; MENEGHETTI, F. K.; SEIFERT, R. E. Por uma crítica ao conceito de desenvolvimento sustentável. Cadernos EBAPE, Rio de Janeiro, v. 10, n. 3, p. 569-583, set. 2012.

Data de Submissão: $30 / 4 / 15$

Data de Aprovação: 9/4/17 